\title{
CONTATO PELE A PELE E ALEITAMENTO MATERNO: EXPERIÊNCIAS DE PUÉRPERAS
}

\section{SKIN-TO-SKIN CONTACT AND BREASTFEEDING: EXPERIENCES OF PUERPERALMOTHERS}

\section{CONTACTO PIEL CON PIEL Y LACTANCIA MATERNA: EXPERIENCIAS DE MUJERES POSPARTO}

\author{
Silvana Mendes Jung ${ }^{1}$, Fernanda Araujo Rodrigues², Silvani Herber ${ }^{3}$
}

\section{RESUMO}

Objetivo: Descrever as experiências de puérperas quanto ao contato pele a pele com o recém-nascido, realizado na primeira hora de vida e o início do aleitamento materno. Método: Trata-se de um estudo exploratório-descritivo, realizado com abordagem qualitativa. A pesquisa foi desenvolvida com puérperas no Alojamento Conjunto de um hospital privado. Para a coleta dos dados foi utilizada a técnica de entrevista semiestruturada. As informações foram submetidas à técnica de análise de conteúdo do tipo temática. Resultados: Foram elaboradas duas categorias: Contato pele a pele, na primeira hora de vida e os sentimentos vivenciados e Vivenciando o início do aleitamento materno. Observou-se que o contato pele a pele não fora realizado, conforme preconizado, mas, apesar disso, as participantes consideraram esse momento como importante, para auxiliar no início do aleitamento materno, pois se sentiram mais confiantes. Conclusão: Identificou-se que a instituição ainda utiliza um modelo intervencionista. Dessa forma, esta pesquisa foi relevante, pois poderá contribuir para a reflexão dos profissionais em relação aos cuidados prestados ao binômio mãe-bebê, possibilitando a qualificação das práticas do contato pele a pele e do aleitamento materno na primeira hora de vida. Descritores: Interação Mãe-Filho; Salas de Parto; Aleitamento Materno; Recém-Nascido; Enfermagem Neonatal.

\begin{abstract}
Objective: To describe the skin-to-skin contact experiences of puerperal mothers with their newborn in the first hour of life and the beginning of breastfeeding. Method: This is an exploratory-descriptive study, conducted with a qualitative approach. The research was developed with puerperal mothers in join accommodation of a private hospital. To collect the information, the semi-structured interview technique was used. The information was submitted to the thematic content analysis technique. Results: Two categories were elaborated: Skin-to-skin contact in the first hour of life and the feelings they had and The experiences in the beginning of breastfeeding. It was observed that the skin-to-skin contact was not performed as recommended, but despite this, the participants considered this moment as important to help in the beginning of breastfeeding, as they felt more confident. Conclusion: It was identified that the institution still uses an interventionist model. Thus, this research was relevant, as it may contribute to the professionals' reflection on the care provided to the mother-baby binomial, enabling the qualification of skin-to-skin contact practices and breastfeeding in the first hour of life.
\end{abstract}

Descriptors: Mother-Child Relations; Delivery Rooms; Breast Feeding; Infant, Newborn; Neonatal Nursing.

\section{RESUMEN}

Objetivo: describir las experiencias de las mujeres posparto con respecto al contacto piel con piel con el recién nacido en la primera hora de vida y el comienzo de la lactancia. Método: este es un estudio exploratorio descriptivo, realizado con un enfoque cualitativo. La investigación se desarrolló con madres en el alojamiento conjunto de un hospital privado. Para recopilar la información, se utilizó la técnica de entrevista semiestructurada. La información se envió a la técnica de análisis de contenido temático. Resultados: se elaboraron dos categorías: Contacto piel con piel en la primera hora de vida y los sentimientos experimentados y experimentando el comienzo de la lactancia materna. Se observó que el contacto piel con piel no se realizó según lo recomendado, pero a pesar de esto, los participantes consideraron que este momento era importante para ayudar al comienzo de la lactancia, ya que se sentían más seguros. Conclusión: se identificó que la institución aún utiliza un modelo intervencionista. Por lo tanto, esta investigación fue relevante porque puede contribuir a la reflexión de los profesionales con respecto a la atención brindada al binomio madre-bebé, permitiendo la calificación de las prácticas de contacto piel con piel y lactancia materna en la primera hora de vida. Descriptores: Relaciones Madre-Hijo; Salas de Parto; Lactancia Materna; Recién Nacido; Enfermería Neonatal.

${ }^{1}$ Enfermeira do Hospital Regina (Novo Hamburgo), Especialista em Enfermagem do Trabalho. ${ }^{2}$ Mestrado em Enfermagem pela Universidade Federal do Rio Grande do Sul, Enfermeira no Departamento de Regulação Estadual da Secretaria de Saúde do Rio Grande do Sul. ${ }^{3}$ Doutora em Ciências Médicas pela Universidade Federal do Rio Grande do Sul, Professora do curso de Graduação em Enfermagem da Universidade Feevale.

Como citar este artigo:

Jung SM, Rodrigues FA, Herber S. Contato pele a pele e aleitamento materno: Experiências de Puérperas. Revista de Enfermagem do Centro Oeste Mineiro. 2020;10:e3657. [Access ]; Available in: . DOI: http://doi.org/10.19175/recom.v10i0.3657 


\section{INTRODUÇÃO}

O Contato Pele a Pele (CPP) entre a puérpera e o Recém-Nascido (RN) realizado ainda em sala de parto, na primeira hora de vida do bebê, é considerado uma das ações de incentivo ao Aleitamento Materno (AM). As evidências apoiando essa prática, são robustas, indicando múltiplos benefícios para mãe e filho ${ }^{(1)}$.

Assim, além de estimular o vínculo mãebebê, o CPP ainda proporciona outros benefícios para o RN, tais como regulação da temperatura corporal, adaptação metabólica, manutenção dos níveis sanguíneos de glicose e manejo da dor ${ }^{(2-3)}$. Também há benefícios para a puérpera, pois 0 toque, o calor e o odor envolvidos nesse processo compreendem em importante estímulo vagal, o qual libera ocitocina, promovendo a contração uterina e reduzindo o risco de hemorragia no período pós-parto ${ }^{(4)}$.

Dessa forma, exceto por alterações clínicas significativas, considera-se essencial que o $\mathrm{RN}$ não seja separado de sua mãe, após o nascimento, devendo ser colocado, precocemente, em CPP para facilitar seu processo de adaptação ao meio extrauterino e, ainda, permitir a autorregulação dos sinais vitais ${ }^{(4)}$. Portanto, recomenda-se que o CPP seja implementado como rotina hospitalar, tornando-a viável para a maioria das puérperas, inclusive em países em desenvolvimento, visto que se trata de uma estratégia de baixo custo ${ }^{(2-3)}$.

Para tal, os tradicionais paradigmas de assistência ao parto e ao nascimento precisam ser modificados $^{(2)}$. Nesse sentido, a Organização Mundial de Saúde (OMS) e o Fundo das Nações Unidas (UNICEF) definiram a realização do CPP como um dos Dez Passos para o sucesso do $\mathrm{AM}^{(5)}$.

Em vista disso, tem-se que o AM precoce e bem-sucedido é uma das consequências da realização do CPP na primeira hora de vida, considerando que tal aproximação entre mãe e RN constitui-se como uma prática facilitadora para a amamentação ${ }^{(2-6)}$. Ainda sobre o $\mathrm{AM}$, já estão devidamente comprovados os seus benefícios em curto, médio e longo prazo, tais como redução do risco de alergias, prevenção de diarreia e infecções respiratórias, diminuição do risco de obesidade infantil, além do efeito positivo no desenvolvimento cognitivo da criança ${ }^{(7)}$.

No entanto, apesar de todas as evidências científicas fundamentando a superioridade do AM sobre outras formas de alimentar o bebê, no Brasil, a taxa de prevalência ainda está bastante aquém das preconizadas, devendo a equipe de saúde atuar para a reversão do quadro ${ }^{(7)}$. Nesse contexto, acredita-se ser fundamental conhecer a percepção das puérperas frente ao início do $A M$, especialmente, após a realização do CPP.

Por conseguinte, a identificação dessas experiências agrega subsídios para a reflexão sobre o trabalho desenvolvido pelos profissionais de saúde, além de ser um importante instrumento para se construir oportunidades de melhorias, proporcionando bem-estar ao binômio mãe-bebê, uma vez que se tornam claros os aspectos envolvidos e os valores atribuídos, na perspectiva de quem recebe a assistência ${ }^{(4-6)}$. Outrossim, ressalta-se que a prevalência de CPP e de amamentação na primeira hora de vida do RN, atualmente, são considerados indicadores de qualidade assistencial, devendo ser monitorados ${ }^{(4)}$.

Diante de tais argumentos e da necessidade de compreender a experiência da puérpera em relação ao $\mathrm{CPP}$ e ao $\mathrm{AM}$, visando a maiores condições para a execução de um cuidado integral $^{(6)}$, justifica-se a realização, desta pesquisa, a qual buscou responder a seguinte questão norteadora: como as puérperas vivenciam o contato pele a pele com o RN, ainda na primeira hora de vida e o início do AM? Portanto, objetivou-se, neste estudo, descrever as experiências de puérperas quanto ao CPP com o $R N$ realizado na primeira hora de vida e o início do AM.

\section{MÉTODOS}

Trata-se de um estudo exploratóriodescritivo, realizado com abordagem qualitativa. Conforme proposto por Minayo, esse método elucida processos sociais pouco explorados, aprofundando-se nos significados das ações e relações, além de possibilitar a identificação e a análise de sentimentos, percepções e comportamento de determinados grupos $^{(8)}$. Desenvolveu-se a pesquisa no Alojamento Conjunto (AC) de um hospital privado, na região do Vale dos Sinos, no estado do Rio Grande do Sul, o qual prioriza a segurança e o bem-estar da puérpera e do $\mathrm{RN}$, sendo referência regional em partos de risco. Participaram do estudo as puérperas que contemplaram os seguintes critérios de inclusão: maiores de idade, que realizaram mais de seis consultas de pré-natal; mães de RN a termo, classificados como adequados para idade gestacional (AIG), sem intercorrências ao nascimento e que, portanto, realizaram o CPP, na primeira hora de vida do bebê. Para definição da amostra, ainda se 
estabeleceram como critérios de exclusão: as puérperas com contraindicação de $\mathrm{AM}$ e/ou as que apresentaram complicações pós-parto. Não houve recusa para a participação da pesquisa.

Para a coleta dos dados, utilizou-se a técnica de entrevista semiestruturada, com perguntas abertas sobre o tema. Cada entrevista teve, em média, 20 minutos de duração e o local escolhido para sua realização foi o próprio quarto da puérpera no $A C$, visando a não afastá-la do seu $\mathrm{RN}$, sendo essa opção considerada adequada e aceita pela participante. As informações foram gravadas e transcritas na íntegra, sendo a identificação da puérpera codificada pela letra " $P$ ", seguida de algarismo numérico, conforme a ordem das entrevistas. O material foi impresso e cada participante validou a veracidade da sua entrevista. Definiu-se a quantidade de entrevistas conforme o critério de saturação dos dados ${ }^{(8)}$.

A organização e o processamento das informações ocorreram com auxílio do software NVivo. Após, visando a atingir o objetivo da pesquisa, empregou-se a técnica de análise de conteúdo do tipo temática, contemplando a préanálise, a exploração do material e tratamento dos dados obtidos e o interpretação ${ }^{(8)}$. Durante a análise, sem alterar o significado das informações fornecidas pelas participantes, realizaram-se pequenos ajustes nos depoimentos, considerando os vícios de linguagem e o fato de que uma das puérperas não possuía a língua portuguesa como língua nativa.

Conduziu-se o projeto de investigação respeitando todos os preceitos éticos relacionados à pesquisa com seres humanos, conforme preconizados pelas Resoluções $n$ 은 466/12 e no 510/16 (9-10), sendo submetido por meio do CAAE 25763913.2.0000.5348 e aprovado pelo respectivo Comitê de Ética em Pesquisa sob o Parecer no 561.492. Ressalta-se que todas as normas do guideline COREQ também foram contempladas $^{(11)}$.

\section{RESULTADOS E DISCUSSÃO}

Participaram do estudo seis puérperas, com idades entre 22 e 33 anos. Em relação à via de parto, três realizaram partos normais e três foram submetidas à cesárea. $\mathrm{O}$ número de consultas de pré-natal não apresentou grande variabilidade, sendo de nove a 11 consultas realizadas. Duas participantes possuíam o ensino médio completo e quatro, o ensino superior completo. Quanto aos RN dessas puérperas, a idade gestacional ao nascimento variou de 37 a 40 semanas.
Em relação à via de parto, ao contrário do observado, nessa investigação, há evidências de que o CPP, geralmente, é realizado, significativamente, com mais frequência em bebês nascidos, por parto vaginal ${ }^{(4-5)}$. Nesse contexto, a cesárea, indubitavelmente, traz à puérpera um desconforto maior, dificultando o contato com o RN nas primeiras horas e dias após o parto ${ }^{(5)}$.

No que tange às consultas de pré-natal, idealmente, recomendam-se condutas de educação relacionadas ao $\mathrm{CPP}^{(1)}$. De modo semelhante, as informações fornecidas são fundamentais para o sucesso do AM. As orientações devem contemplar a preparação das mamas e o posicionamento correto do $\mathrm{RN}^{(7)}$. No entanto, apenas duas participantes relataram receber tal tipo de informação. Ainda, outras variáveis também podem influenciar, como tipo de mamilos, experiência prévia em amamentação, situação econômica e escolaridade materna ${ }^{(5-12)}$.

A partir da análise das informações obtidas, construíram-se duas categorias temáticas, as quais são discutidas a seguir.

\section{Contato pele a pele na primeira hora de vida e os sentimentos vivenciados}

Nessa categoria, as puérperas relataram suas experiências quanto ao CPP realizado na primeira hora de vida do RN, incluindo o momento em que o bebê foi entregue a elas e os sentimentos vivenciados. Quanto ao momento do CPP, algumas puérperas relataram sobre o tempo de realização dessa prática, conforme evidenciado abaixo: "Ficou pouco tempo (...) ele só ficou assim do meu ladinho, [os profissionais] tiraram rápido" (P2). "Foi uma meia hora a quarenta e cinco minutos" (P3).

Em relação ao tempo para a realização do CPP, recomenda-se que a prática deva iniciar, imediatamente, após o nascimento e mantenhase por, pelo menos, uma hora ${ }^{(5)}$, diferentemente do que foi encontrado nesta investigação. No entanto, estudo observacional, realizado com 111 díades mãe-bebê, identificou que a média de duração do CPP foi de 30 minutos $^{(4)}$.

Reitera-se que o CPP consiste em colocar o bebê nu e seco no tronco/abdômen da puérpera, em contato direto, imediatamente após o nascimento ${ }^{(5)}$. Nesse contexto, os relatos das participantes ainda permitiram identificar que, na maioria dos casos, o CPP não foi realizado conforme preconiza a literatura. Os depoimentos abaixo confirmam esse aspecto: "Prepararam ela, fizeram todo preparo de qualquer outra criança 
(...) depois me trouxeram ela" (P5). "A pediatra pegou, [os profissionais] enrolaram ele (...)levaram ele ali pra caminha para limpar (...) e já trouxeram pra mim" (P6).

Na prática, sabe-se que o binômio mãebebê pode vivenciar o CPP de formas distintas ${ }^{(4)}$. No entanto, os mesmos autores evidenciaram em sua pesquisa que a prevalência de CPP exclusivo foi de $53,2 \%$, enquanto $18,9 \%$ realizaram, exclusivamente, o contato denominado "pelepano" e $27,9 \%$ realizaram ambos os tipos de contato, durante a primeira hora de vida ${ }^{(4)}$.

Os achados desta investigação corroboram os resultados de outro estudo, na qual o CPP e o início da amamentação ocorreram somente após o RN ter sido assistido pela equipe de saúde, sendo entregue à puérpera envolto por cobertores e/ou cueiros $^{(6)}$. No entanto, considerando um grupo de $\mathrm{RN}$ a termo, com peso e Apgar adequados, assim como os envolvidos, nesta pesquisa, espera-se uma mínima necessidade de intervenção, podendo-se priorizar o CPP entre mãe-bebê $\hat{~}^{(4)}$.

Em contrapartida, estudo recente que avaliou 82 puérperas internadas em $A C$ identificou que $95 \%$ das participantes realizaram o CPP com seu bebê, o que foi considerado um resultado muito satisfatório, o qual expressa o empenho dos profissionais e a qualidade da assistência prestada $^{(13)}$. Ainda, outra pesquisa identificou que metade das 107 puérperas entrevistadas referiram ter realizado o CPP ainda nos primeiros 30 minutos de vida do seu RN, porém, apenas 9,3\% mantiveram o contato, por mais de 30 minutos ou até que eles realizassem a primeira mamada $^{(14)}$.

Nesta pesquisa, a única participante que recebeu sua filha de forma imediata, após o nascimento, relatou que não percebeu a presença do $\mathrm{RN}$ devido à exaustão relacionada ao trabalho de parto e parto. O trecho a seguir ilustra essa questão: "[Os profissionais] botaram ela em cima da minha barriga, eu só soube que ela estava sobre a minha barriga quando o meu marido apontou para ela, porque eu não sentia nada" (P1).

Portanto, a partir dos depoimentos das puérperas, identifica-se que a maioria dos RN recebeu assistência profissional imediata, sendo levado ao encontro da mãe apenas após a realização de alguns procedimentos. Portanto, percebe-se uma assistência tecnicista, com rotinas assistenciais que ainda preconizam que, imediatamente após o nascimento, tenha-se como prioridade a realização de procedimentos no RN, mesmo em situações em que este se encontra sem necessidade de manobras de estabilização ${ }^{(14)}$.

Tal fato remete a refletir sobre fatores que podem desfavorecer a prática do CPP, tais como a ausência de protocolos institucionais para a realização do CPP ou a alta demanda de serviço, com necessidade de liberação da sala de parto. Em relação a esse último fator, pesquisa recente constatou que a carga de trabalho, por vezes, interfere na realização do CPP na primeira hora de vida $^{(2)}$.

Sabe-se que os profissionais de saúde possuem uma função relevante nesse contexto ${ }^{(4)}$. Sendo assim, a equipe multiprofissional deve garantir que todas as providências sejam tomadas para viabilizar o CPP, tais como garantir que o avental da puérpera seja colocado de modo a permitir o acesso do RN, imediatamente, após o parto $^{(1)}$.

Nessa lógica, visando a apoiar as metas do milênio de melhoria da saúde materno-infantil, recomenda-se fornecer a todos os profissionais atuantes em sala de parto, programas educacionais e de capacitações contínuas sobre como implementar o $\mathrm{CPP}^{(2)}$. Tal fato ainda se justifica, pois, nas primeiras horas após o nascimento, deve-se proporcionar à díade mãebebê um ambiente o mais adequado possível, atentando para a temperatura do local, além do controle de ruídos e de luminosidade ${ }^{(4)}$.

A partir das declarações, também se identificou que as participantes relataram os sentimentos vivenciados, durante a realização do CPP, como ansiedade. O depoimento abaixo confirma esse aspecto: "Eu estava super ansiosa, toda hora eu perguntava pra eles [profissionais] que horas iam trazer meu bebê, e a cada dois minutos parecia que passava meia hora, porque eu via ele só de longe, não tinha como pegar ele, ainda não tinha sentido o cheirinho dele, nada" (P3).

Percebe-se a ansiedade de uma das puérperas, em razão de não prover do contato com seu filho, logo ao nascer, embora ela tenha recebido seu $\mathrm{RN}$ ainda dentro da primeira hora pós-parto. Logo após o trabalho de parto e o nascimento, a mãe pode sentir-se exausta e o contato com o bebê pode gerar sentimentos negativos, tais como ansiedade, medo, preocupação e insegurança no desempenho da função materna. Por isso, a equipe de saúde deve 
estar sensibilizada para respeitar o tempo da díade mãe-bebê $\hat{e}^{(15)}$.

No entanto, a maioria das participantes relataram sentimentos positivos quanto à experiência do CPP com seu filho. Os trechos, a seguir, ilustram essa questão: "É bem o que falam, não tem como a gente descrever (...). É só emoção, a gente não para de olhar, fica o tempo todo olhando. Foi indescritível" (P4). "Quando colocaram ele perto de mim, que eu senti o cheirinho. Nossa! Não tem explicação, é algo inexplicável, é maravilhoso!" (P6).

A partir dos relatos, percebe-se que o contato entre a díade mãe-bebê, logo após o parto, foi considerado como um momento singular, para o qual algumas puérperas não encontraram palavras suficientes para expressar a experiência, considerando o quão grandioso reflete nelas o primeiro encontro com seu concepto. Assim, o nascimento do filho desperta novas emoções, revelando a nova vida.

Portanto, infere-se que, nesta investigação, todas as puérperas identificaram que O CPP realizado na primeira hora, mesmo que realizado de forma breve e de forma não imediata ao nascimento, agregou benefícios para a construção do vínculo entre a mãe e filho, despertando fortes sentimentos. Assim, tem-se que o CPP produz felicidade, amor, tranquilidade e conforto para puérpera e bebê $\hat{~}^{(6)}$.

\section{Vivenciando o início do aleitamento materno}

Nessa categoria, as participantes da pesquisa relataram suas experiências quanto ao início do AM; o desejo em amamentar, bem como suas expectativas e sentimentos. Há evidências de que amamentar é um processo complexo que envolve o estado nutricional da criança, a sua imunidade, a sua fisiologia e o seu desenvolvimento cognitivo, além de ter implicações na saúde física e psíquica da puérpera ${ }^{(7)}$.

Nesse cenário de pesquisa, entre os seis RN que realizaram o CPP, quatro sugaram, sendo dois nascidos por parto vaginal e dois por cesárea. Os depoimentos abaixo comprovam tais vivências: "Grudou [no seio], como se ela soubesse o que era" (P1). "Ele já pegou [o seio] com muita força" (P3). "Sim, sugou na primeira" (P4). "Ele sugou bem forte!" (P6).

Tem-se que o início tardio do AM, aquele realizado após a primeira hora de vida, eleva o risco de mortalidade neonatal ${ }^{(16)}$. Dessa forma, a amamentação precoce deve ser fortemente incentivada pelos profissionais de saúde atuantes em centro obstétrico. Nesse sentido, consideramse de extrema relevância condutas de educação em sala de parto, que venham auxiliar e esclarecer às mulheres sobre 0 assunto ${ }^{(6)}$.

No entanto, sabe-se que, embora os benefícios da realização imediata do CPP e do AM precoce tenham sido, amplamente, pesquisados e validados, menos da metade dos $\mathrm{RN}$, em todo o mundo, são amamentados ainda na primeira hora de vida ${ }^{(16)}$. Nessa investigação, duas participantes não vivenciaram tal experiência na primeira hora de vida, conforme apresentado nas falas abaixo: "Ele [recém-nascido] só ficou assim do meu ladinho" (P2). "Não [sugou], ela só quis dormir" (P5).

Sabe-se ainda que a cesariana possa interferir na interação mãe-bebê, em decorrência do uso de medicamentos que podem influenciar o estado de consciência da puérpera e de seu filho ${ }^{(7)}$. No entanto, nesse cenário de pesquisa, esse fato não se caracterizou pelo tipo de parto, pois uma puérpera teve seu filho via cesárea e a outra por parto vaginal. Ressalta-se, ainda, que, em ambos os casos, o desejo de amamentar já existia desde a confirmação da gestação.

Ainda quanto à expectativa do $\mathrm{AM}$, todas as puérperas se referiram à vontade de amamentar, apesar de alguns receios. Suas escolhas podem estar relacionadas a vivências prévias, às condições culturais ou ao conhecimento adquirido, durante o período gestacional. Os depoimentos abaixo confirmam tais desejos: "Quando eu soube que eu estava grávida, já sabia que eu queria amamentar" (P1). "Desde o início que eu soube [da gestação], eu queria muito amamentar" (P5).

Há evidências de que é fundamental a mulher apresentar disposição para amamentar, fato que não deve ser considerado apenas como um aspecto biológico, pois o AM é um processo constituído por inúmeros valores, sendo influenciado por fatores psicológicos e socioculturais ${ }^{(6)}$. Em algumas circunstâncias, esse desejo de amamentar está baseado no conhecimento materno quanto aos benefícios do Leite Materno (LM), conforme os relatos abaixo: "Quando ela estava na minha barriga, eu dizia pra ela: filha, você tem que mamar! (...) Senão a gente vai gastar muito dinheiro com leite em pó e tu vais ficar muito doente" (P1). "Os benefícios que traz para o bebê e para mãe também (...) Mas eu acho que ao bebê mais, pelo carinho, pela vitamina, por tudo que passa pra ele" (P6). 
A partir das declarações, percebeu-se que as puérperas identificam como benefícios do LM: provimento de vitaminas, troca de carinho, redução do peso da puérpera e inclusive a economia, visto ser menos oneroso que as fórmulas industrializadas. Nesse sentido, estudos evidenciaram que as mães apresentavam consciência quanto aos benefícios do AM e o consideravam como fator de proteção frente a doenças, sendo essencial para a saúde do bebêt ${ }^{6-}$ 17).

Nesse sentido, o sentimento da puérpera ao ofertar todos os benefícios que o LM traz ao bebê gera uma sensação de realização para essa mãe ${ }^{(17)}$. Além disso, a superação das dificuldades que permeiam todo o processo do AM também traz para esta puérpera um sentimento de satisfação e felicidade ${ }^{(18)}$.

No entanto, alguns sentimentos negativos também podem estar presentes em determinados momentos do AM, como, por exemplo, a ansiedade e a frustração de não saciar o filho ${ }^{(18)}$. Nesse cenário de pesquisa, os sentimentos mais citados foram a ansiedade e o receio em amamentar seus filhos. Em relação à ansiedade, essa estava, principalmente, relacionada à quantidade de leite produzido e ofertado, conforme apresentado no depoimento abaixo: "Já estou ansiosa para que desça logo o leite, porque ainda não desceu" (P6).

Nesse contexto de insegurança, as puérperas precisam de suporte ativo, inclusive emocional, assim como orientações objetivas, para desenvolver a confiança necessária ${ }^{(7)}$. Assim, para apoiar o processo de aleitamento materno, a equipe de saúde precisa compreender qual o tipo de suporte, informação e interação as puérperas desejam, necessitam ou esperam ${ }^{(7)}$.

No entanto, em relação à confiança em amamentar, uma das puérperas relatou otimismo desde o período gestacional, apesar de não saber como seria o processo de AM, pelo fato de ser seu primeiro filho. O trecho abaixo ilustra esse aspecto: "Eu sempre achei que eu ia dar certo, sabe? 0 fato de não ter experiência(...) Mas parece que de um momento para outro você sabe como funcionam as coisas" (P2).

Reitera-se que a amamentação pode trazer benefícios psicológicos a díade mãe-bebê, pois o contato contínuo entre a puérpera e o seu filho aumenta a afetividade, trazendo sentimentos de segurança e de proteção para o bebê, além de elevar a autoconfiança e a realização da materna ${ }^{(7)}$. Desse modo, infere-se que, neste estudo, as participantes vivenciaram momentos de ansiedade e receio, o que pode ter dificultado - AM; porém, esses foram superados pela determinação das puérperas em alimentar seus filhos, permitindo a transmissão de todos os benefícios do LM ao bebê.

\section{CONSIDERAÇÕES FINAIS}

Atingiu-se o objetivo do estudo a partir da construção das categorias temáticas, as quais descreveram as experiências das puérperas quanto ao CPP realizado na primeira hora de vida e ao início do AM. No entanto, identificou-se que a instituição ainda utiliza um modelo intervencionista, logo após o parto, o que pode ter dificultado a realização do CPP conforme preconiza a literatura, ou seja, com o RN desnudo em contato direto com a sua mãe, imediatamente após o parto. Tal fato gerou ansiedade nas puérperas, mas, apesar disso, as participantes consideraram esse momento como importante tanto para elas quanto para o bebê, demonstrando sentimentos positivos.

Em relação ao início do $A M$, apesar de não ser o foco desta investigação, observou-se que o ato de o RN sugar o seio materno na primeira hora de vida foi igualmente distribuído entre as puérperas que realizaram parto vaginal e cesariana. Ainda, para o sucesso do processo do AM, deve-se iniciar as orientações ainda no período gestacional. No entanto, poucas mães relataram ter recebido informações sobre AM e CPP. Desse modo, recomenda-se que o enfermeiro inicie as orientações, desde as consultas de pré-natal para que a mãe possa conhecer os benefícios do CPP. Além disso, a preparação, durante a gestação, favorece para que a mãe se torne confiante em receber seu filho, evitando receios desnecessários e permitindo que ela se entregue ao prazer no momento do contato com seu filho.

Assim, nos últimos anos, o Ministério da Saúde (MS) vem trabalhando para melhorias no atendimento à mulher e à criança no pré-natal, parto, puerpério e puericultura. Para isso, o MS lançou protocolos e orientações para os profissionais da saúde, além de trazer incentivos para as instituições de saúde. Dentre as orientações está a realização do CPP entre mãe e bebê, na primeira hora de vida, a importância do AM e em quais momentos essa orientação deve ser realizada.

Neste estudo, descreveram-se as percepções das puérperas em relação ao CPP. Tais 
achados demonstraram fragilidades na realização dessa prática. Portanto, tem-se como implicações para as ações de enfermagem a necessidade de orientar a realização correta da técnica, bem como assegurar condições adequadas para tal. Além disso, este estudo possibilitou compreender o quão fundamental é a realização de capacitações dos profissionais, que realizam as consultas de pré-natal e/ou os atuantes em centros obstétricos.

Salienta-se como limitações deste estudo, a realização em apenas uma instituição hospitalar, a qual incentiva o aleitamento materno exclusivo do nascimento aos seis meses de vida, bem como a continuidade da amamentação, após esse período. Portanto, não condiz em sua totalidade com a realidade de outros serviços. No entanto, esta pesquisa torna-se relevante, pois os resultados poderão contribuir para a reflexão dos profissionais quanto aos cuidados prestados ao binômio mãe-bebê, possibilitando a qualificação das práticas do CPP e do AM na primeira hora de vida. Ainda, percebe-se a necessidade de outros estudos, em diferentes cenários, para melhor avaliar as possíveis lacunas na assistência à puérpera e seu RN, garantindo, assim, as condutas preconizadas para a humanização da atenção obstétrica.

\section{REFERÊNCIAS}

1- Widström AM, Brimdyr K, Svensson K, Cadwell $K$, Nissen E. Skin-to-skin contact the first hour after birth, underlying implications and clinical practice. Acta Paediatr. 2019;108:1192-204. DOI: 10.1111/apa.14754

2- Safari K, Saeed AA, Hasan SS, MoghaddamBanaem $L$. The effect of mother and newborn early skin-to-skin contact on initiation of breastfeeding, newborn temperature and duration of third stage of labor. Int Breastfeed J. 2018;13(1):32. DOI: 10.1186/s13006-018-0174-9

3- Lotto CR, Linhares MBM. Contato "pele a pele" na prevenção de dor em bebês prematuros: revisão sistemática da literatura. Trends Psychol. 2018;26(40):1699-713. DOI: 10.9788/TP2018.4-01 4- Abdala LG, Cunha MLC. Contato pele a pele entre mãe e recém-nascido e amamentação na primeira hora de vida. Clin Biomed Res 2018;38(4):356-60. DOI: 10.4322/23579730.82178

5- Cinquetti $M$, Colombari AM, Battisti E, Marchetti P, Piacentini G. The influence of type of delivery, skin-to-skin contact and maternal nationality on breastfeeding rates at hospital discharge in a baby-friendly hospital in Italy. Pediatr Med Chir. 2019;41(1):17-21. DOI: 10.4081/.2pmc019.207.

6- D'artibale EF, Bercini LO. O contato e a amamentação precoces: Significados e vivências. Texto Contexto-Enferm. 2014; 23(1):109-17. DOI: 10.1590/S0104-07072014000100013

7- Brasil, Ministério da Saúde (MS). Saúde da criança: Aleitamento materno e alimentação complementar. 2a ed. Brasília: Ministério da Saúde; 2015.

8- Minayo MCS. O desafio do conhecimento: Pesquisa qualitativa em saúde. 14a ed. São Paulo: Hucitec; 2014.

9- Brasil, Ministério da Saúde. Resolução CNS/MS $n^{\circ} 466$, de 12 de dezembro de 2012. Diário Oficial da União 2012.

10- Brasil, Ministério da Saúde. Resolução CNS/MS n ${ }^{\circ}$ 510, de 7 de abril de 2016. Diário Oficial da União 2016.

11- Tong A, Sainsbury P, Craig J. Consolidated criteria for reporting qualitative research (COREQ): A 32-item checklist for interviews and focus groups. Int J Qual Health Care 2007;19(6):349-57. DOI: 10.1093/intqhc/mzm042 12- Carreiro JA, Amorim FA, Vilhena AACF, Oliveira MK, Sá Vieira AES, Pereira CK. Dificuldades relacionadas ao aleitamento materno: Análise de um serviço especializado em amamentação. Acta Paul Enferm. 2018;31(4):430-8. DOI: 10.1590/1982-0194201800060.

13- Romão RS, Fuzissaki MA, Prudêncio PS, Freitas EAM. Qualidade da assistência obstétrica relacionada ao parto por via vaginal: Estudo transversal. Rev Enferm Cent-Oeste Min. 2018;8:e2907. DOI: 10.19175/recom.v8i0.2907.

14- Sampaio ARR, Bousquat A, Barros C. Contato pele a pele ao nascer: Um desafio para a promoção do aleitamento materno em maternidade pública no Nordeste brasileiro com o título de Hospital Amigo da Criança. Epidemiol Serv Saúde 2016;25(2):281-90. DOI: 10.5123/s1679-49742016000200007

15- Santos LM, Silva JCR, Carvalho ESS, Carneiro AJS, Santana RCB, Fonseca MCC. Vivenciando o contato pele a pele com o recém-nascido no pósparto como um ato mecânico. Rev Bras Enferm. 2014; 67(2):202-7. DOI: 10.5935/00347167.20140026

16- Cadwell K, Brimdyr K, Phillips R. Mapping, measuring, and analyzing the process of skin-toskin contact and early breastfeeding in the first hour after birth. Breastfeed Med. 2018:13(7):48592. DOI: $10.1089 / \mathrm{bfm} .2018 .0048$. 
17- Wilhelm LA, Demori CC, Alves CN, Cremonese CNBL, Ressel LB. A vivência da amamentação na ótica de mulheres: Contribuições para a enfermagem. Rev Enferm UFSM 2015;5(1):160-8. DOI: $10.5902 / 2179769215409$.

18- Orso LF, Mazzetto FMC, Siqueira FPC. Percepção de mulheres quanto ao cenário de cuidado em saúde na promoção do aleitamento materno. Rev Recien 2016;6(17):3-12. DOI: 10.24276/rrecien2358-3088.2016.6.17.3-12

Nota: Artigo extraído do Trabalho de Conclusão de Curso (Graduação em Enfermagem - Universidade Feevale) intitulado: Visão das mães sobre o contato pele a pele com o recém-nascido na primeira hora de vida e o sucesso do aleitamento materno.

Recebido em: 09/02/20

Aprovado em: 05/06/20

Endereço de correspondência: Rua Dona Oti, 190/402. CEP: 90680-060

e-mail: sherber@hcpa.edu.br 